\title{
Federalismo e Igualdade Territorial: Uma Contradição em Termos?*
}

\author{
Marta Arretche \\ Professora livre-docente do Departamento de Ciência Política da Universidade de São Paulo \\ (USP). E-mail: arretche.usp.br
}

\begin{abstract}
expressão "natureza particular do federalismo brasileiro" é emA pregada por analistas do regime democrático instituído pela Constituição de 1988 para designar uma das instituições que tendem a afetar negativamente a efetividade do Estado brasileiro na provisão de políticas públicas.
\end{abstract}

A adoção da fórmula federativa seria, em primeiro lugar, uma espécie de artificialismo, dado que a sociedade brasileira não apresenta as clivagens étnicas ou religiosas que justificariam a adoção de arranjos consociativos (Lamounier, 1992). Além disto, a fórmula adotada no Brasil estaria entre as mais descentralizadas do mundo (Shah, 2006), o que conferiria excessiva autonomia aos governos locais e, por consequência, limitados incentivos para a cooperação horizontal. Relações

\footnotetext{
* Este artigo é uma versão revisada de trabalho publicado sob a forma de working paper do Departamento de Política e Ciências Sociais do European University Institute, intitulado: "Federalism and place-equality policies: A case study of policy design and outputs", assim como de versões preliminares apresentadas em encontros do European Consortium for Political Research (em Rennes, 2006), e da International Political Science Association (em Santiago, em 2009). A pesquisa que deu origem a este trabalho foi realizada no Centro de Estudos da Metrópole, com suporte da Fundação de Amparo à Pesquisa do Estado de São Paulo (Fapesp). Seus resultados fazem parte de um projeto comparativo sobre finanças públicas locais, no âmbito do International Metropolitan Observatory (IMO). Agradeço os comentários e sugestões de Jefferey Sellers, Charles Jeffery, Fernando Rezende, Daniel Vazquez e Sandra Gomes, bem como dos pareceristas anônimos da DADOS. Sou grata a Edgard Fusaro e Daniel Arias Vazquez pela valiosa colaboração na coleta e tratamento dos dados estatísticos.
}

DADOS - Revista de Ciências Sociais, Rio de Janeiro, vol. 53, nº3, 2010, pp. 587 a 620. 
intergovernamentais predatórias e ausência de coordenação seriam o resultado deste federalismo autárquico (Abrucio e Soares, 2001). Dado o poder de veto dos interesses locais nas arenas decisórias federais, negociações distributivas seriam uma das moedas de troca da política brasileira, dado que o pork barrel, via emendas ao orçamento, seria um dos instrumentos centrais empregados pelos presidentes para obter a cooperação dos parlamentares (Pereira e Mueller, 2002). Por fim, se, de um lado, o federalismo contribui para a fragilidade dos partidos, de outro, esta mesma fragilidade explicaria as débeis relações entre as políticas executadas pelos governos subnacionais e a filiação partidária de seus governantes (Ribeiro, 2005; Sakurai, 2009).

Em conjunto, as instituições federativas, tal como desenhadas pelos constituintes de 1988, comprometeriam a eficiência e efetividade do Estado brasileiro. Entre outros fatores, este arranjo institucional tornaria extremamente custoso - se não, impossível - que este garanta os direitos de cidadania, de acordo com a proposição de Marshall (1967), segundo a qual o status de cidadão operaria como um instrumento de garantia de igualdade em contraposição ao princípio de desigualdade próprio à inserção na sociedade de mercado.

Este artigo sustenta que estas interpretações chamam a atenção para traços presentes do Estado e do sistema político brasileiros. Entretanto, superdimensionam sua relevância, pois ignoram duas dimensões centrais: o papel das desigualdades regionais na escolha da fórmula federativa adotada no Brasil bem como a importância das relações entre a União e os governos subnacionais sobre seu funcionamento.

A interpretação de que os governos subnacionais têm excessiva autonomia está baseada na evidência empírica de que a parcela dos governos subnacionais na arrecadação e gasto público consolidado no Brasil é bastante elevada quando comparada a outras federações. Adicionalmente, a interpretação se baseia na extensão das competências subnacionais na execução de políticas públicas, bem como no status dos municípios na federação, características que são de fato peculiares ao arranjo institucional brasileiro.

A inferência de que a vida política brasileira é dominada por negociações particularistas (leia-se, transferências negociadas) está, por sua vez, baseada em proposições relativas ao impacto das regras eleitorais sobre o comportamento dos parlamentares. 
Em suma, autonomia dos governos subnacionais e regras eleitorais produziriam incentivos perversos sobre os cálculos de governantes locais e parlamentares. Seus resultados comprometeriam a capacidade de integração territorial e social do Estado brasileiro, função central dos Estados modernos.

Este artigo argumenta que incluir na análise as desigualdades territoriais, bem como as relações entre a União e os governos subnacionais nos leva a uma interpretação mais precisa acerca das motivações para a adoção da fórmula federativa no Brasil e de seus resultados. A despeito da inexistência de clivagens religiosas ou étnicas, a nação brasileira é historicamente dividida entre jurisdições pobres e ricas. Se as primeiras não têm expressão política relevante, a clivagem entre unidades constituintes pobres e ricas está na origem da escolha por um desenho de Estado que permita "manter a União" e evitar os riscos associados à fórmula majoritária, nos termos da clássica formulação de Lijphart (1984). Garantir o equilíbrio da representação das e nas jurisdições ricas e pobres foi, historicamente, um componente central do desenho das instituições políticas brasileiras ${ }^{1}$.

A segunda premissa analítica diz respeito às relações central-local. A descentralização da execução de políticas é compatível com a centralização da autoridade, mesmo em estados federativos (Obinger et alii, 2005). Estudos comparados revelaram que a governança local/intermediária/estadual é fortemente afetada pelas relações central-local (Sellers e Lidström, 2007; Razin, 2007), assim como as prioridades políticas dos governos subnacionais podem ser largamente afetadas pela estrutura de incentivos derivada de suas relações com níveis superiores de governo (Arretche, 2000) ${ }^{2}$. A análise adequada destas relações requer distinguir duas dimensões distintas de autoridade: a formulação e a execução de políticas públicas. Como propôs Pierson (1995:451), em estados federativos, a questão de "quem deve fazer o quê" se superpõe à questão de "o quê deve ser feito".

Distinguir quem formula de quem executa permite inferir que, no caso brasileiro, embora os governos subnacionais tenham um papel importante - e até mesmo pouco usual em termos comparados - no gasto público e na provisão de serviços públicos, suas decisões de arrecadação tributária, alocação de gasto e execução de políticas públicas são largamente afetadas pela regulação federal. 
A legitimidade da regulação federal, por sua vez, tem raízes profundas na formação do Estado-nação brasileiro. O princípio de que a União deve estar dotada de instrumentos para legislar e supervisionar a ação dos governos subnacionais tem sua base de legitimidade tanto na ideia de nação (isto é, no sentimento de pertencimento a uma comunidade nacional única) quanto na desconfiança com relação às práticas das elites políticas locais.

Para explorar este problema, este artigo percorre o seguinte caminho analítico. Toma como variável dependente a provisão de serviços básicos; assume que esta é uma maneira de avaliar um dos resultados esperados dos mecanismos postos em operação pelo federalismo brasileiro. Isto é, se "as instituições federativas são relevantes para as políticas públicas" (Stepan, 1999:239), um caminho para avaliar este impacto é medir a oferta de serviços públicos.

No caso brasileiro, este caminho analítico autoriza tomar os municípios brasileiros como unidade de análise ${ }^{3}$. Seguindo tendência internacional (Banting, 2006), as políticas de garantia de renda permaneceram sob responsabilidade da União (previdência, compensação ao desemprego e programas assistenciais), ao passo que as políticas de prestação de serviços passaram a ser executadas pelos governos territoriais. Entretanto, diferente de outras federações, no Brasil os serviços básicos de saúde, educação, infraestrutura urbana, habitação, saneamento e coleta de lixo são executados pelos governos municipais.

O segundo passo da análise consiste em identificar os efeitos das relações central-local sobre a desigualdade na oferta de serviços municipais. Em primeiro lugar, assumindo que os municípios são desiguais, é possível avaliar o papel redistributivo dos níveis superiores de governo antes e depois do "tratamento" produzido pela regulação federal das receitas subnacionais. Portanto, é possível conectar os efeitos de redução das desigualdades associadas às regras do jogo tributário e fiscal da federação brasileira. Por outro lado, assumindo que os municípios brasileiros são iguais enquanto unidades de produção de serviços públicos, a existência de políticas reguladas de maneiras diferentes permite explorar os efeitos da regulação federal sobre o gasto dos governos locais.

Em suma, as relações central-local são uma variável analítica central. Seus efeitos sobre as decisões dos governos municipais, bem como sobre a desigualdade entre jurisdições, permite testar a proposição relati- 
va aos efeitos deletérios das instituições federativas brasileiras sobre a produção de políticas públicas. A análise cobre o período 1996-2006, com base no Banco de Dados sobre Informações Municipais do Centro de Estudos da Metrópole.

$\mathrm{O}$ artigo fornece evidências para argumentar que estados federativos que concentram autoridade regulatória na União criam mecanismos institucionais que operam na direção da redução das desigualdades. Contudo, a possibilidade de divergência dos governos locais, uma característica intrínseca de estados federativos, tende a produzir mecanismos que operam no sentido da divergência de políticas entre jurisdições. Consequentemente, estados federativos que combinam regulação centralizada e autonomia política dos governos locais tendem a restringir os patamares da desigualdade territorial. Este resultado é explicado por duas tendências apenas aparentemente contraditórias, isto é, o papel regulatório do governo central opera no sentido da uniformidade, ao passo que a autonomia dos governos locais opera no sentido da divergência de políticas. Esta interação implica desigualdade entre as jurisdições, mas esta tende a variar no interior de certos intervalos. Nestes contextos, a desigualdade territorial tende a ser limitada.

Este artigo está organizado em quatro seções, além desta introdução e das conclusões. A primeira seção sumariza os argumentos das principais teorias institucionais sobre as relações entre federalismo e desigualdade entre jurisdições. A segunda explora as origens da centralização da autoridade política no federalismo brasileiro, destacando aspectos centrais do processo de construção do Estado-nação. A terceira seção descreve as regras e políticas da regulação federal sobre as receitas dos governos municipais e examina seu impacto redistributivo. A quarta seção examina a regulação federal dos gastos dos governos locais, bem como seus efeitos sobre a desigualdade territorial.

\section{EXPECTATIVAS DAS TEORIAS EXISTENTES}

As teorias institucionais nos permitem esperar três distintos resultados em estados federativos no tocante à desigualdade de políticas entre as jurisdições. Uma das mais influentes argumenta que federalismo implica desigualdade, pois "[...] a uniformidade é antitética ao federalismo [...], não há saída para um fato decisivo: federalismo e igualdade de resultados não podem coexistir" (Wildavsky, 1984:57-68). 
Este resultado seria produzido por um mecanismo institucional básico: estados federativos garantem a possibilidade da discordância por parte das unidades constituintes. A possibilidade de discordância cria mecanismos institucionais que favorecem a diversidade de políticas. Uma vez que as jurisdições podem discordar entre si ou com o governo central, o resultado inevitável seria a desigualdade das políticas implementadas.

A teoria da escolha pública, por sua vez, desenvolveu um modelo ideal de federação a partir do influente artigo de Charles Tiebout (1956), segundo o qual governos locais eficientes e responsáveis requerem instituições políticas que promovam a competição por contribuintes com mobilidade interjurisdicional. Com base nesta premissa, Weingast (1995) e Buchanan (1995) propuseram um modelo ideal de Estado nacional, no qual (i) a autoridade sobre políticas (policy decision-making) e sobre a execução das políticas (policy-making) deveria ser altamente descentralizada; e (ii) o papel redistributivo do governo central deveria ser fortemente limitado.

Para estes autores, não é realista esperar que governos centrais possam eficientemente desempenhar funções redistributivas. Políticas distributivas não seriam capazes de produzir redução das desigualdades territoriais porque estas tendem, inevitavelmente, a converter-se em pork barrel, isto é, gastos localizados cuja alocação refletiria interesses clientelistas de coalizões regionais poderosas nas arenas decisórias centrais.

Assim, as proposições teóricas desta escola nos permitem esperar dois possíveis resultados em estados federativos. O primeiro se refere aos resultados prováveis na presença de políticas nacionais de tipo distributivo. Em tais contextos, as transferências seriam dirigidas aos distritos de origem das elites políticas com maior poder regional. Estes não seriam necessariamente os distritos mais necessitados. Como resultado, portanto, políticas distributivas não obteriam resultados redistributivos.

Um segundo resultado estaria associado aos contextos federativos nos quais há competição, entre as jurisdições, por cidadãos e firmas que "votam com os pés" (Tiebout, 1956). Este contexto conduziria a uma "corrida para baixo" nas políticas redistributivas, porque a estratégia dominante dos governos locais seria livrar-se dos pobres para atrair firmas e contribuintes mais ricos (Peterson, 1995). Portanto, em ne- 
nhum dos cenários possíveis, estados federativos produziriam redução das desigualdades territoriais.

Finalmente, uma terceira escola argumenta que estados federativos não são antitéticos à redução das desigualdades entre jurisdições. Diferentemente, estes podem criar instituições que reduzam eficientemente estas desigualdades, sendo a Alemanha o caso mais estudado. Este resultado, contudo, requer centralização da autoridade política.

O argumento sustenta que "[r]edistribuição [territorial] significativa somente pode ser alcançada pelo nível nacional" (Obinger, Leibfried e Castles, 2005:352), posto que seria "[...] a especificidade do aparato regulatório estabelecido pelo nível central e a extensão da redistribuição interregional de recursos que estabelece os fundamentos estruturais do equilíbrio entre cidadania social e diversidade regional" (Banting e Corbett, 2002:22).

Portanto, em estados federativos que centralizem a formulação de políticas executadas pelas unidades constituintes e que contem com um sistema interjurisdicional de transferências, é possível encontrar redução das desigualdades territoriais. Assim, de acordo com esta teoria, os papéis regulatório e redistributivo do governo central seriam mecanismos necessários para obter cooperação entre jurisdições.

Entretanto, este compromisso somente seria possível em estados federativos com frágeis identidades regionais, isto é, aqueles em que a nação coincida territorialmente com o Estado. Na tradição de Stein Rokkan, este supõe que os cidadãos partilhem um sentimento comum de pertencimento a uma comunidade nacional única.

Reduzir desigualdades territoriais, por outro lado, teria um preço. Este tende a ser um jogo de soma zero, isto é, se o governo central ganha poder de decisão, estando, portanto, autorizar a regular os níveis inferiores de governo, estes últimos perdem poder e sua autoridade decisória será necessariamente limitada.

Observe-se que as expectativas da escola da escolha pública e do neoinstitucionalismo histórico são compatíveis, posto que ambas partilham o suposto teórico de que há um trade-off entre redistribuição - ou redução das desigualdades territoriais - e a centralização da autoridade política. 


\section{ORIGENS DA CENTRALIZAÇÃO: CONSTRUÇÃO DO ESTADO-NAÇÃO}

Em algumas federações, o processo de construção do Estado-nação foi acompanhado de um compromisso com regras homogêneas nacionais. Tal como a Alemanha (Manow, 2005) e a Áustria (Obinger, 2005), o processo de construção do Estado-nação no Brasil concentrou autoridade decisória, assim como poder regulatório e de gasto no governo central. Orientações normativas solidamente instaladas tenderam a dar maior prioridade a políticas nacionais homogêneas do que a demandas por autonomia regional. A desigualdade entre as jurisdições para desempenhar adequadamente funções governativas deu origem à centralização na União das funções tributárias, de planejamento, e mesmo de execução de políticas. Paralelamente, ao longo do século XX, regimes autoritários (1930-1934; 1937-1945 e 1964-1985) chegaram a suprimir a autonomia política das unidades subnacionais por longos períodos.

A centralização de autoridade na União ocorreu, na verdade, já no final da República Velha. Esta foi derivada da percepção, por parte das elites, dos riscos para o conjunto da nação associados à incapacidade das províncias periféricas desempenharem funções governativas, seja na área social (Hochman, 2006) seja na área econômica (Oliveira, 1977; Schwartzman, 1982) ${ }^{4}$. A partir dos anos 30, a União teve um papel central no planejamento e financiamento da atividade econômica, o que supôs centralização da autoridade política (Draibe, 1985; Nunes, 1997; Sikkink, 1993; Souza, 1976). A centralização da arrecadação tributária permitiu ao Estado desenvolvimentista brasileiro destinar expressivos volumes de receita para compensar desigualdades territoriais. Estas foram acompanhadas da supervisão federal das políticas implementadas pelos governos territoriais (Arretche, 2005).

A supervisão federal dos governos territoriais também foi justificada pela avaliação de que a política local era domínio da corrupção e do clientelismo (Leal, 1949). Os autoritários dos anos 1920 propiciaram a justificativa normativa para o regime autoritário instalado em 1930, ao sustentar que a autonomia política dos estados era um instrumento por meio do qual oligarquias regionais atrasadas manipulavam e exploravam eleitores ignorantes e, deste modo, impediam as iniciativas de um governo central modernizador (Mota, 1982). Combater a corrupção e o clientelismo locais esteve também presente na justificação para a supressão da autonomia política dos estados pelo regime militar instalado em 1964 (Carvalho, 2001). Por fim, mais recentemente a 
legislação federal que regulou as finanças dos governos subnacionais a partir de meados dos anos 90 foi justificada, na Câmara dos Deputados, com base no argumento de que matérias de tamanha importância não poderiam ser deixadas nas mãos dos políticos locais (Arretche, 2007; 2009).

Portanto, longe de uma visão tieboutiana, a noção de que a intervenção federal na política local pode ser uma maneira eficiente de proteger os cidadãos contra elites políticas atrasadas e corruptas tem raízes profundas na história brasileira. Nos dias atuais esta visão é partilhada pelas elites progressistas, mesmo aquelas favoráveis à descentralização da execução de políticas públicas (Almeida, 2005).

Entretanto, regras nacionais homogêneas não significam necessariamente resultados igualitários; diferentes fatores explicam as desigualdades social e regional no Brasil. Em primeiro lugar, o crescimento econômico foi concentrado nas regiões Sul e Sudeste. Esta se reflete em grande variação na capacidade de arrecadação própria dos governos subnacionais. Ainda que o reconhecimento deste fato esteja na origem de políticas fiscais redistributivas, estas historicamente produziram limitada compensação para desigualdades territoriais de capacidade de extração de recursos tributários.

No plano social, desde sua origem, nos anos 30 , as políticas sociais nacionais estiveram inspiradas nos valores normativos do modelo conservador (Draibe, 1989), de acordo com a tipologia de Esping-Andersen (1990), isto é, visaram fundamentalmente a produzir status diferenciados entre categorias de cidadãos. Os direitos de cidadania foram desigualmente atribuídos de acordo com a inserção no mercado formal de trabalho, assim como os benefícios sociais estavam vinculados às contribuições e aos rendimentos dos trabalhadores. Em um contexto de elevados desemprego e desigualdade de renda, estas regras de titularidade reforçaram a exclusão e a segregação, em vez de reduzir desigualdades socioeconômicas.

Assim, o processo de construção do Estado-nação no Brasil deu uma resposta centralizadora aos desafios da penetração e da integração territoriais, da construção econômica e da participação política e social (Almond e Powell, 1978). Elevadas taxas de crescimento econômico foram acompanhadas de elevada desigualdade na distribuição espacial e social da riqueza, que se concentrou no Sul e Sudeste. Além disto, o desemprego e a inserção informal no mercado de trabalho, combina- 
das a um modelo bismarckiano de direitos sociais, implicaram amplas parcelas de cidadãos desprovidos de proteção social. Por fim, no plano da participação, a resposta do Estado desenvolvimentista significou substituir direitos sociais por direitos políticos e civis, bem como dividir os cidadãos de acordo com princípios corporativos (Santos, 1979; Carvalho, 2001).

As políticas atuais de redução das desigualdades territoriais são o resultado da combinação desta trajetória centralizadora com reformas fiscais e políticas aprovadas no período democrático recente, desde a Constituição de 1988 até nossos dias. Os traços bismarckianos das políticas sociais da era Vargas e do regime militar foram compensados por políticas desmercadorizantes ${ }^{5}$ : a universalização da saúde e da educação, bem como o componente não-contributivo da previdência social. Na mesma direção, a regulamentação e supervisão federais sobre as políticas dos governos subnacionais foi expandida a partir dos anos 1990, comprometendo estes últimos a dar prioridade aos gastos com educação e saúde, bem como com a disciplina fiscal, entre outras medidas. Em outras palavras, uma sólida tradição de regulação federal foi, mais uma vez, empregada para implementar políticas de compensação das desigualdades sociais e territoriais.

Em suma, além de um sentimento comum de pertencimento a uma única comunidade nacional (conceito de nação), a desconfiança na disposição das elites locais para implementar e respeitar os direitos dos cidadãos pode ser uma poderosa fonte de centralização da autoridade política, mesmo em estados federativos. Nestas circunstâncias, mesmo elites progressistas favoráveis à descentralização da execução de políticas públicas tendem a preferir que o governo central regule o modo como estas políticas serão implementadas, de modo a amarrar as mãos de governadores e prefeitos que, se supõe, possam pretender converter os recursos recebidos em políticas conservadoras, corruptas ou clientelistas.

\section{POLÍTICAS NACIONAIS DE REDUÇÃO DE DESIGUALDADES TERRITORIAIS}

Como já destacado, uma adequada interpretação de polities em que a execução de políticas é descentralizada requer o emprego da distinção conceitual entre responsabilidade pela execução de políticas públicas (policy-making) e a autoridade para tomar decisões sobre estas mesmas políticas (policy decision-making). Isto implica evitar a inferência analí- 
tica, frequentemente empregada, de deduzir a segunda a partir de evidências empíricas sobre a primeira. Na verdade, grande parte das proposições sobre a autonomia dos governos subnacionais no Brasil é comprometida por esta indistinção conceitual.

Adotar esta distinção analítica, por sua vez, permite uma interpretação bastante mais acurada da federação brasileira, bem como da dinâmica de implementação das políticas descentralizadas. Dados os processos históricos sumarizados na seção anterior, a União tem grande capacidade de iniciativa. As decisões de arrecadação tributária e de gasto dos governos subnacionais - tanto de estados quanto de municípios - são significativamente limitadas pela legislação nacional. Além disto, a provisão de serviços públicos e a alocação setorial do gasto são fortemente afetadas pela legislação e supervisão federais. Como consequência, embora as unidades constituintes sejam politicamente autônomas e tenham responsabilidade na arrecadação de tributos e de execução de políticas, sua autonomia decisória não pode ser adequadamente interpretada, se ignorarmos a extensão em que a agenda dos governos subnacionais é afetada pela regulação federal. Portanto, examinar desigualdades territoriais de acesso dos cidadãos brasileiros a políticas públicas requer incluir a regulação federal na análise.

\section{Políticas Nacionais de Redução das Desigualdades de Receita}

A autoridade tributária das unidades constituintes no Brasil é regida por regras federais homogêneas. Governos locais ou estaduais não estão autorizados a coletar impostos livremente, mesmo que seus cidadãos aceitassem pagá-los. Diferentemente de um mundo tieboutiano, os governos municipais no Brasil estão autorizados a taxar apenas a propriedade urbana, os serviços e a transferência de propriedade. Embora esta possa parecer uma ampla base tributária, sua autoridade tributária está limitada à definição das alíquotas de arrecadação destes impostos. Portanto, a autonomia tributária dos governos municipais no Brasil está limitada à definição das alíquotas de seus próprios impostos.

Além de sua arrecadação própria, os governos municipais contam, ainda, com transferências. E estas, entretanto, são regidas por critérios distintos de distribuição. As transferências constitucionais podem ser federais ou estaduais. Das federais, a mais importante é o Fundo de Participação dos Municípios (FPM), que tem orientação redistributiva, 
embora sua efetividade seja bastante controversa ${ }^{6}$. Este Fundo é composto por 23,5\% das receitas dos dois principais impostos federais: o Imposto de Renda e o Imposto sobre Produtos Industrializados (IPI). Dez por cento são distribuídos entre as capitais, e os restantes $90 \%$ são distribuídos entre as demais cidades, sendo cada quota individual calculada por uma fórmula inversamente proporcional à população e à receita per capita do respectivo estado (Afonso e Araújo, 2006). Na prática, esta fórmula está congelada desde 1989 (Rezende, 2006).

As transferências constitucionais estaduais, por sua vez, operam segundo o princípio da devolução tributária. Isto é, os estados devem distribuir para seus próprios municípios com $25 \%$ do total da arrecadação do Imposto sobre a Circulação de Mercadorias e Serviços (ICMS), bem como com 50\% das receitas do Imposto sobre a Propriedade de Veículos Automotores (IPVA). Setenta e cinco por cento do montante a ser distribuído deve ser calculado segundo a arrecadação em cada jurisdição ${ }^{7}$.

Por fim, um terceiro componente das receitas municipais são as transferências condicionadas universais. Estas se converteram em universais a partir do final dos anos 90 e são, portanto, uma componente recente das políticas de redução das desigualdades territoriais de receita; além disto, estão vinculadas a políticas específicas. Na saúde, tornaram-se universais desde $1998^{8}$, uma vez completado o longo processo de adesão voluntária ao Sistema Único de Saúde (SUS), iniciado em 1990. Estas transferências estão vinculadas a ações de saúde, que variam desde o atendimento a serviços básicos até $\mathrm{o}$ atendimento hospitalar. São universais no sentido de que todos os municípios que cumpram os requisitos estabelecidos pelas Normas Operacionais do Ministério da Saúde estão aptos a recebê-las. Também são universais porque quase $100 \%$ dos municípios brasileiros operam segundo as regras do SUS.

Na política de educação, as transferências vinculadas são universais porque todos os governos subnacionais estão obrigados, pela Constituição Federal, a depositar 20\% de suas receitas de impostos e transferências federais em um fundo contábil cuja redistribuição opera no âmbito de cada estado. Para cada fundo estadual, as receitas são distribuídas de acordo com as matrículas oferecidas por cada rede de ensino ${ }^{9}$. 
O Gráfico 1 apresenta o impacto de cada uma destas fontes na receita média dos governos municipais. Se estes contassem apenas com sua arrecadação própria, sua receita média, ao longo do período 1996-2006, teria girado em torno de $\mathrm{R} \$ 100$ per capita. As transferências constitucionais - federais e estaduais - acrescentam um significativo montante de recursos aos cofres municipais. Cresceram ao longo do período, elevando o patamar médio das receitas municipais para cerca de R\$ 800 per capita, em 2006. Já constituíam, contudo, de longe sua principal fonte de receita desde o início da série. As transferências condicionais universais, por sua vez, têm um impacto positivo adicional. Cresceram significativamente a partir de sua introdução, em 1988, e elevavam a receita média para cerca de $\mathrm{R} \$ 1.000$, em 2006.

As demais transferências, como pode ser observado no gráfico, têm pequeno impacto orçamentário. O dado não é irrelevante, pois revela que o impacto das transferências negociadas sobre as receitas municipais é marginal, muito pouco expressivo quando comparado ao das demais modalidades de transferência.

Portanto, a parte mais expressiva das receitas municipais está fora de barganhas políticas, posto que sua distribuição está definida por regra constitucional. Logo, embora as transferências negociadas possam ter

\section{Gráfico 1}

Receitas dos governos municipais por fonte

Brasil - 1996-2006

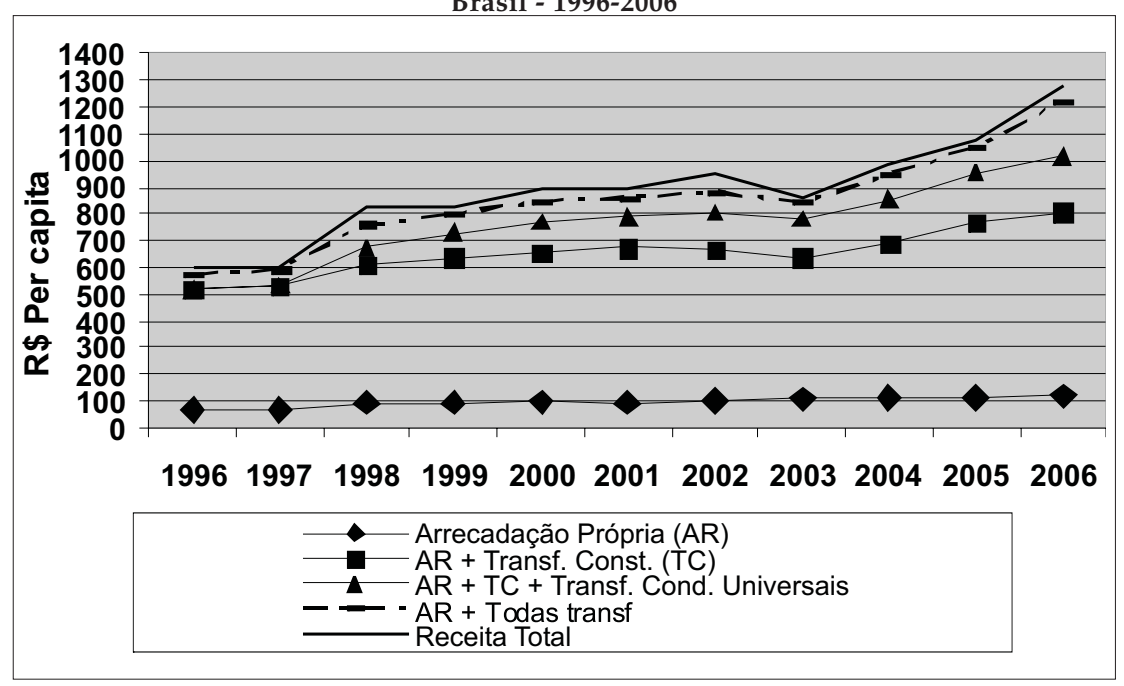

Fonte: Banco de Informações Municipais do Centro de Estudos da Metrópole. 
alguma relevância nas negociações políticas entre o presidente e os parlamentares, seu impacto sobre os recursos municipais é provavelmente bem menos relevante do que se supõe. Prefeitos contam com recursos da União, independentemente de lealdades partidárias ou comportamento parlamentar. Embora recursos adicionais possam ser bem-vindos, a oferta de serviços públicos locais não depende de relações políticas, sejam elas partidárias ou individuais.

\section{Efeitos sobre a desigualdade territorial de receita}

A maior parte das análises estatísticas sobre o impacto das transferências constitucionais não distingue as transferências federais das estaduais. Uma exceção é o trabalho de Biderman (2005), que as desagregou e demonstrou que as transferências federais são progressivas, e as estaduais, regressivas. De fato, levar as regras da relação central-local a sério requer esta distinção, pois, como vimos acima, a alocação destas transferências é regida por princípios distintos.

O Gráfico 2 desagrega as diferentes fontes de receitas dos municípios brasileiros e apresenta seus respectivos coeficientes de Gini ${ }^{10}$. Este está calculado para a arrecadação própria e para cada uma das fontes de receita adicionais. Os índices medem, portanto, o impacto de cada uma

\section{Gráfico 2}

Desigualdade de receita por fonte

Municípios Brasileiros - 1996-2006

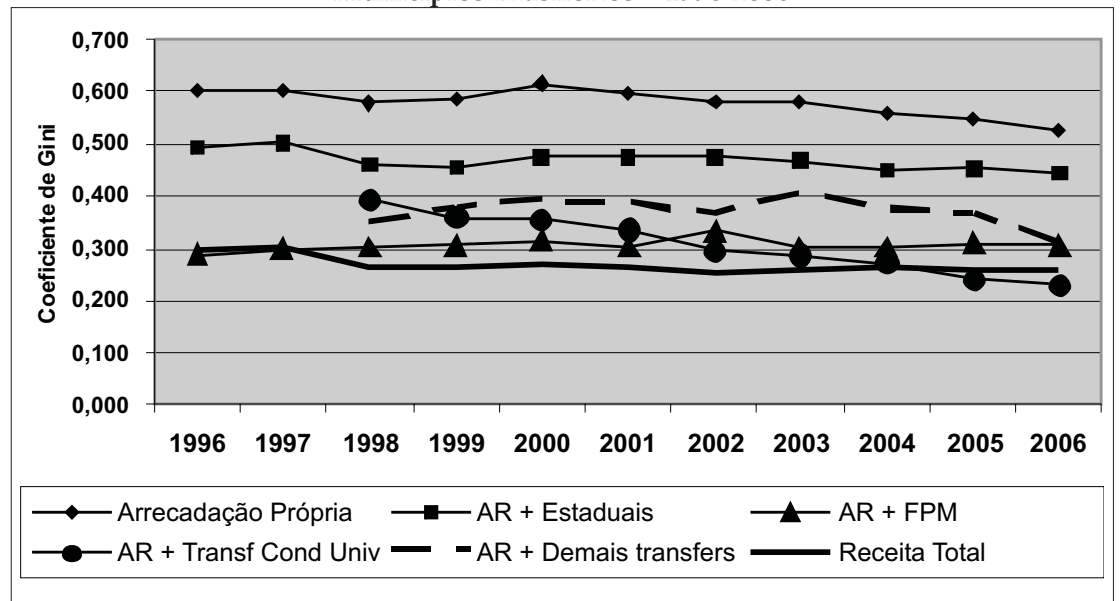

Fonte: Banco de Informações Municipais do Centro de Estudos da Metrópole. 
das fontes sobre a desigualdade de receita em relação à arrecadação direta.

Assim, se os municípios brasileiros contassem apenas com os recursos de sua arrecadação própria, sua capacidade de gasto seria altamente desigual, a julgar pelo Coeficiente de Gini deste indicador (próximo a 0,550, em 2006, embora declinante ao longo da série). Se os municípios brasileiros contassem apenas com as transferências constitucionais estaduais, além de sua arrecadação própria, seriam menos desiguais, pois a entrada desta fonte de receita nos cofres municipais reduz o Coeficiente de Gini para um patamar em torno de 0,450 (embora este fosse de 0,500 no início da série). Este patamar de desigualdade pode ser encarado como o mais próximo da desigualdade efetiva da riqueza gerada nos municípios, pois as transferências estaduais são devolução tributária. Em outras palavras, a arrecadação tributária própria, somada às transferências estaduais, reflete, em grande medida, a desigualdade de atividade econômica entre os municípios brasileiros.

As receitas do FPM têm significativo efeito de redução das desigualdades de receita. Sua entrada nos cofres municipais reduz o Coeficiente de Gini para cerca de 0,300, excluídas todas as demais fontes de transferência. Isto é, se os municípios brasileiros contassem apenas com sua arrecadação própria e com as receitas do FPM, sua desigualdade de receita cairia pela metade. Lembre-se que os dados do Gráfico 1 indicam que esta fonte, somada às transferências constitucionais estaduais, é o principal componente das receitas municipais.

O Fundo de Manutenção e Desenvolvimento do Ensino Fundamental e Valorização do Magistério (FUNDEF) e a Norma Operacional Básica 96 (NOB-96), do SUS - classificadas como transferências condicionadas universais - foram efetivamente implantados em 1998, razão pela qual a linha das transferências condicionadas universais se inicia neste ano. Seu impacto redistributivo é significativo. Se esta fosse a única fonte de receita dos municípios, além de sua arrecadação própria, seu efeito na redução das desigualdades de receita seria semelhante ao do FPM. A partir de 2003, estas passaram a ter um impacto mais significativo do que todas demais fontes na redução das desigualdades de receita entre as jurisdições. Isoladamente, são seguramente as mais redistributivas, pois em 2006 as transferências do SUS e do FUNDEF reduziam o Coeficiente de Gini para 0,220. Entretanto, é importante 
não esquecer que seu impacto global sobre as receitas municipais é pequeno (ver Gráfico 1).

As demais transferências - isto é, todas aquelas que não são regulamentadas pela legislação - também têm um importante efeito de redução das desigualdades, particularmente a partir de 2003. Contrariando as expectativas da teoria da escolha pública, estas transferências não parecem reforçar ou reproduzir desigualdades derivadas da riqueza instalada em cada jurisdição, ainda que seu impacto redistributivo seja mais limitado que o do FMP, ou do SUS e do FUNDEF combinados.

Por fim, combinadas todas as fontes, a desigualdade de receita entre os municípios brasileiros gira em torno de um Coeficiente de Gini de 0,280 , índice muito inferior àquele derivado de uma suposta adoção da fórmula tieboutiana ou, ainda, no qual a União não tivesse nenhum papel de coordenação sobre as receitas. Diferentemente, a União cumpre de maneira clara um papel de redução das desigualdades de receita entre os municípios brasileiros. Quer tomemos qualquer das transferências federais - FPM, SUS e FUNDEF e mesmo as transferências negociadas -, os dados acima não confirmam a proposição de que as jurisdições mais ricas são aquelas que mais se beneficiam do papel redistributivo da União. Mais que isto, a redução das desigualdades não está associada a negociações políticas, orientadas à formação de coalizões de apoio ao presidente. Em vez disso, esta opera segundo mecanismos altamente previsíveis, posto que regulados por regras constitucionais ou infraconstitucionais.

\section{Políticas nacionais de regulamentação e supervisão do gasto}

Regras que vinculam as receitas dos governos subnacionais ao gasto em políticas específicas são um componente central das políticas federais de regulação das políticas descentralizadas. Estas limitam a autonomia decisória das unidades constituintes com relação à alocação de seus próprios recursos.

Estas regras, como já mencionado anteriormente, não são um componente novo da regulação federal dos governos subnacionais no Brasil. De fato, "amarrar" as unidades constituintes a modalidades desejadas de gasto por meio de mandatos constitucionais foi um mecanismo adotado já na Constituição de 1946, para vincular uma pequena parcela das receitas das unidades constituintes a políticas de desenvolvimento. O mesmo princípio foi adotado em constituições posteriores. Mais 
recentemente, a Emenda Calmon e a Constituição de 1988 vincularam receitas dos governos municipais à educação (Arretche, 2005).

Portanto, a novidade das vinculações adotadas pela legislação federal a partir de meados dos anos 90 diz respeito às áreas privilegiadas e às taxas de vinculação. Pelo menos $40 \%$ das receitas municipais devem ser alocadas nas áreas de saúde e educação, respectivamente, 25\% para educação ${ }^{11}$ e $15 \%$ para saúde ${ }^{12}$.

Por outro lado, nas áreas de desenvolvimento urbano - qual seja, infraestrutura urbana, habitação, transporte público e coleta do lixo-, a regulamentação federal é bem mais limitada. Embora os governos municipais recebam transferências para executar estas políticas, elas não são nem universais nem regulares. Além disto, o gasto nestas políticas não é determinado constitucionalmente. Em outras palavras, nestas políticas, os governos subnacionais têm parcela considerável de autonomia de implementação.

Logo, é possível distinguir dois tipos de políticas descentralizadas:

(1) reguladas: aquelas nas quais a legislação e a supervisão federais limitam a autonomia decisória dos governos subnacionais, estabelecendo patamares de gasto e modalidades de execução das políticas.

(2) não reguladas: aquelas nas quais execução das políticas (policy-making) está associada à autonomia para tomar decisões (policy decision-making).

Neste estudo, as políticas reguladas são aquelas de educação e saúde, ao passo que as não reguladas são as de desenvolvimento urbano, mais especificamente, habitação, infraestrutura urbana e transporte público.

Observe-se, entretanto, que esta distinção analítica não é um atributo da política pública, mas, sim, um atributo da relação central-local, que afeta, por sua vez, a autonomia decisória do nível de governo encarregado de sua execução. Em um cenário hipotético, no qual uma determinação constitucional obrigasse estados e municípios a gastar $1 \%$ de suas receitas com habitação converteria esta área em uma política regulada. Do mesmo modo, uma política federal que criasse transferências regulares e universais para a política de transporte das regiões metropolitanas, vinculando estas transferências à execução de determi- 
nados programas, converteria esta em uma política regulada nos municípios pertencentes a esta categoria.

É, portanto, o emprego dos recursos institucionais da União para regular a execução descentralizada de uma dada política que a converte em uma política regulada. Dadas as características do federalismo brasileiro, esta possibilidade existe potencialmente para qualquer área de política pública.

\section{Efeitos das políticas de regulação do gasto}

O conceito de regulação adotado neste trabalho diz respeito à regulamentação e à supervisão federais sobre as políticas executadas pelos governos subnacionais. Como os municípios brasileiros são "unidades iguais" enquanto prestadores de serviços públicos, é possível examinar o efeito de presença (ou não) da regulação federal sobre o comportamento do gasto.

Dois efeitos interconectados, porém distintos, podem ser examinados. O primeiro diz respeito à discordância entre as jurisdições, e o segundo diz respeito à desigualdade territorial. A extensão em que os governos subnacionais discordam entre si, ou em relação ao governo federal, pode ser medida pela prioridade conferida a cada política setorial. Esta pode ser avaliada, portanto, pelo nível de gasto. A desigualdade de gasto, por sua vez, diz respeito à distância entre uma situação hipotéti$\mathrm{ca}$, em que todas as jurisdições teriam o mesmo gasto per capita e o gasto per capita efetivo. Este pode ser medido pelo Coeficiente de Gini.

O Gráfico 3 apresenta, sob a forma de box-plot, a variação do percentual de gasto em saúde para todos os municípios brasileiros no período 2002- $6^{13}$. Como pode ser observado, a prioridade do gasto em saúde é comparativamente alta entre os municípios brasileiros; os percentuais variam entre $10 \%$ e $30 \%$ do gasto total; metade dos municípios está muito próxima à mediana, que varia em torno de $20 \%$ do total das receitas municipais. Entretanto, se considerarmos todos os municípios, observe-se que há um razoável nível de discordância, no sentido de que, além dos outliers, um quarto dos municípios gasta dez pontos percentuais acima da mediana, e a outra metade gasta comparativamente pouco em saúde, na verdade, tende a gastar menos do que o determinado pela Constituição ${ }^{14}$. 
Gráfico 3

Percentual do gasto em saúde sobre o gasto total municípios brasileiros - 2002-2006

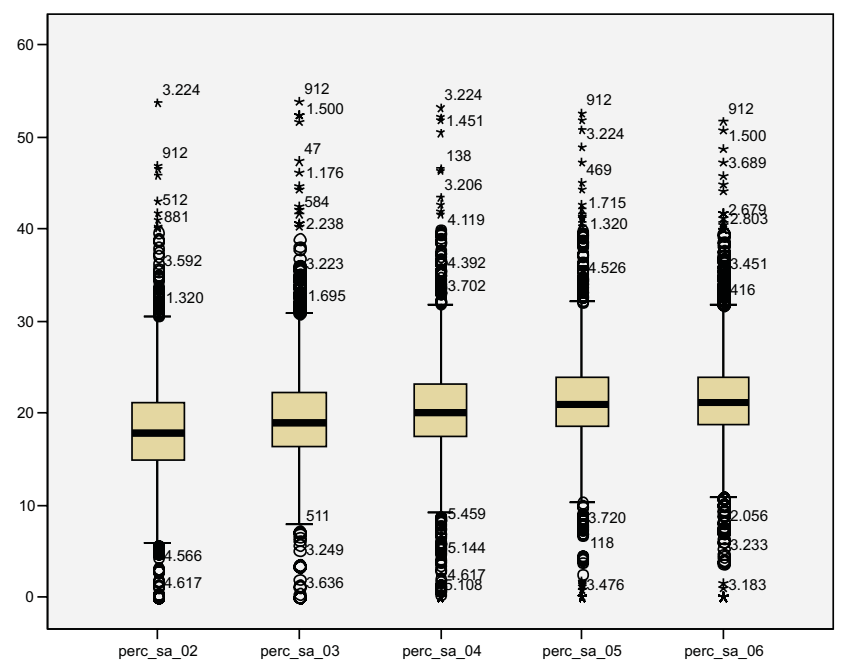

Fonte: Banco de Informações Municipais do Centro de Estudos da Metrópole.

O box-plot do Gráfico 4 apresenta os mesmos dados, porém refere-se à educação. Para metade dos municípios brasileiros, a variação na prioridade de gasto nesta área gira em torno de um valor mediano próximo a 25\%, o que indica que estes atendem à regra constitucional. O intervalo de variação do conjunto dos municípios, por sua vez, está entre $10 \%$ e $50 \%$ do gasto total. Nesta política particular, embora a variação interna seja maior, encontramos um comportamento semelhante ao encontrado para a saúde. Como comportamento padrão, os municípios brasileiros conferem alta prioridade ao gasto em educação.

O Gráfico 5 apresenta os mesmos dados para as áreas de habitação e urbanismo. Em primeiro lugar, indicam que esta modalidade de gasto tem menor prioridade nas decisões de gasto no comportamento padrão dos municípios. Vinte e cinco por cento destes alocaram entre zero e $5 \%$ de seus gastos nesta área. Observe-se, ainda, que a variação em torno da mediana (por volta de $10 \%$ do gasto total) é um pouco maior do que aquela observada para as políticas reguladas. Em suma, estes dados indicam que as políticas de habitação e infraestrutura urbana têm muito menor prioridade na agenda dos governos municipais.

Por fim, o Gráfico 6 apresenta as mesmas informações para o gasto em transporte público. Esta política tem claramente baixa prioridade de 
Gráfico 4

Percentual do gasto em educação sobre o gasto total municípios brasileiros - 2002-2006

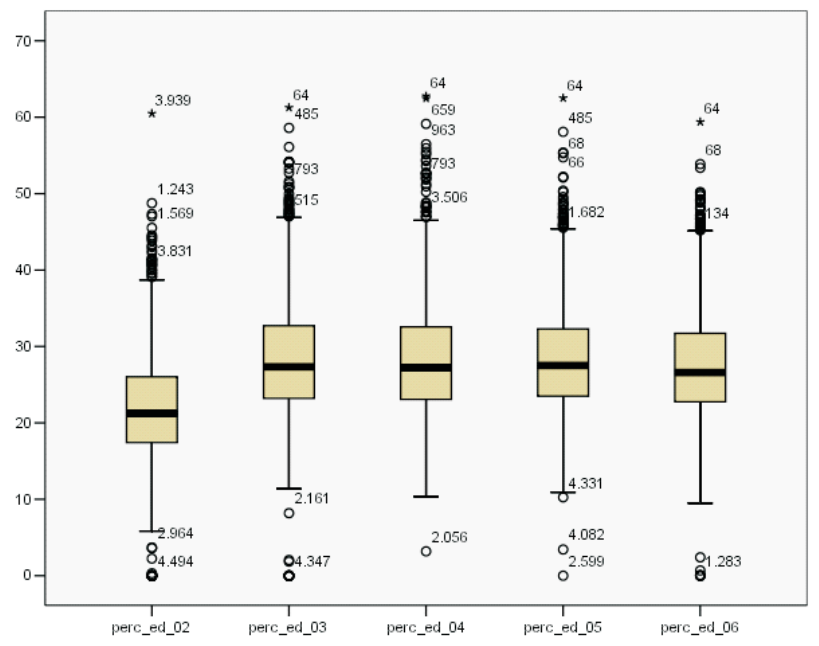

Fonte: Banco de Informações Municipais do Centro de Estudos da Metrópole.

\section{Gráfico 5}

Percentual do gasto em habitação e urbanismo sobre o gasto total municípios brasileiros - 2002-2006

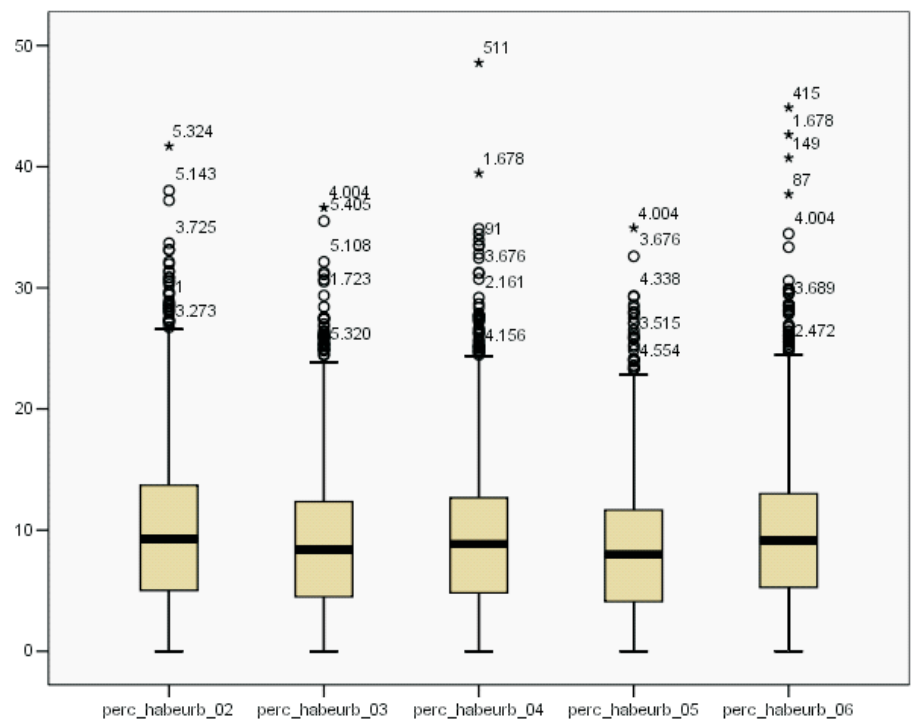

Fonte: Banco de Informações Municipais do Centro de Estudos da Metrópole. 
Gráfico 6

Percentual do gasto em transporte sobre o gasto total municípios brasileiros - 2002-2006

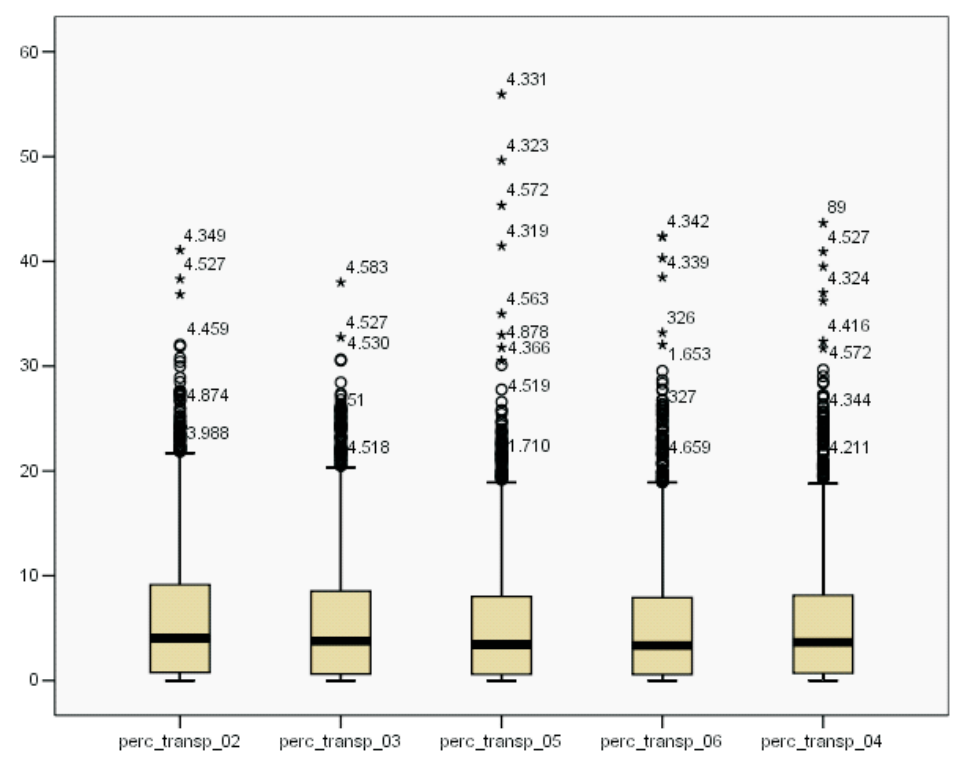

Fonte: Banco de Informações Municipais do Centro de Estudos da Metrópole.

gasto para o conjunto dos municípios; tende a ser um comportamento bastante homogêneo, isto é, há concentração em torno da mediana, inferior a $5 \%$, bem como $2 \%$ dos municípios aplicaram, nesse período, percentuais próximos a "zero", o que, em termos de agenda local, significa prioridade de equivalente teor. A despeito disto, um conjunto de outliers gasta em transporte bem mais do que o percentual compreendido entre zero e $20 \%$ do gasto total.

Em suma, as prioridades de gasto dos municípios brasileiros apresentam um claro padrão. As políticas reguladas têm alta prioridade na alocação do gasto municipal, ao passo que as políticas não reguladas não têm prioridade de gasto. Este comportamento não é resultado de um padrão aleatório; antes, é explicado pelas relações central-local, isto é, pelo efeito de convergência produzido pela legislação e supervisão federais.

Por outro lado, não podemos ignorar as variações na prioridade conferida às diferentes políticas. A despeito da regulação, há minorias de municípios que discordam das prioridades dos demais. 


\section{Gráfico 7}

Desigualdade de gasto por função

municípios brasileiros - 1996-2006

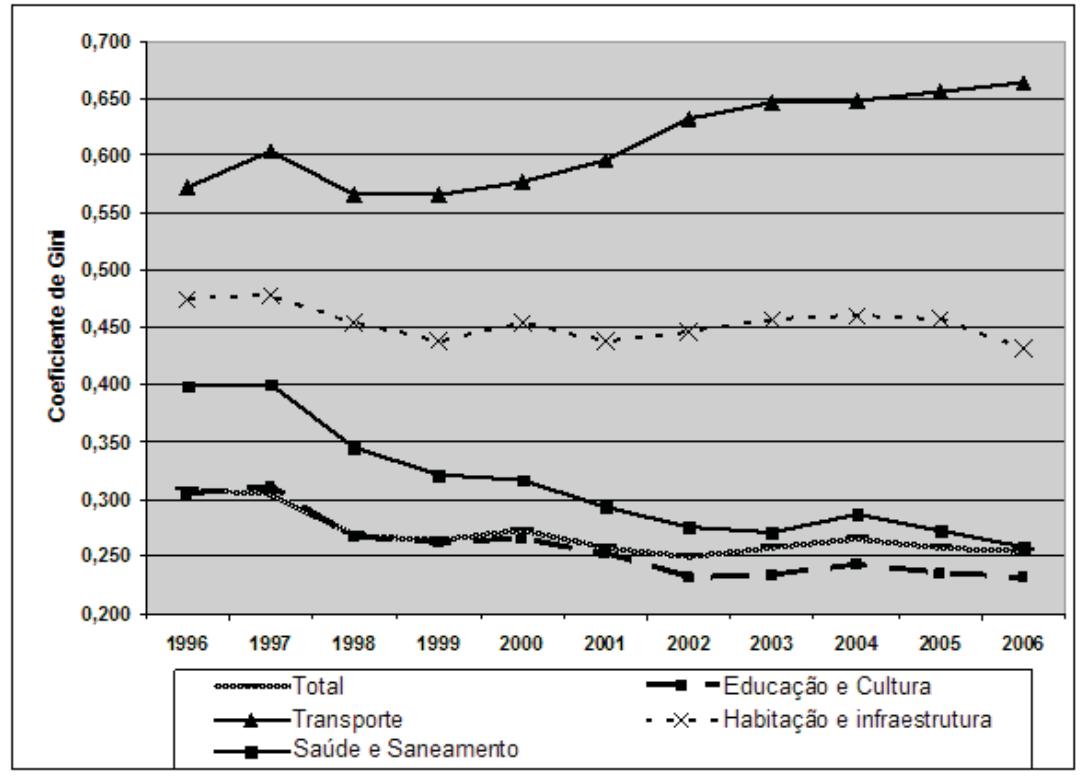

Fonte: Banco de Informações Municipais do Centro de Estudos da Metrópole.

Passemos ao problema da desigualdade. O Gráfico 7 apresenta os Coeficientes de Gini para o gasto municipal em cada uma das políticas examinadas ${ }^{15}$, para o período $1996-2006^{16}$. Como se pode observar, políticas reguladas e não reguladas apresentam comportamento claramente distinto; a desigualdade horizontal de gasto nas políticas reguladas é bem menor do que nas políticas não reguladas.

A despesa em educação e cultura apresentava o menor Coeficiente de Gini já em 1996 (0,304). A introdução do Fundef reduziu ainda mais os índices de desigualdade no gasto: de 0,266, em 1998, para 0,232, em 2006. A função saúde e saneamento, por sua vez, apresentava um Coeficiente de Gini bastante superior ao observado na função educação e cultura (0,399) em 1996. A implementação da NOB 96/98 implicou redução da desigualdade deste gasto para 0,345, em 1998. Além disto, a introdução da Emenda Constitucional 29/2000 implica nova inflexão do índice de Gini, que cai para 0,293, em 2001, com trajetória decrescente da curva até o último ano da série: 0,259, em 2006. 
Os coeficientes das políticas reguladas ficam praticamente iguais a partir de 2004, quando as transferências condicionadas e a vinculação de receitas estão plenamente implantadas nas políticas de saúde e de educação. Isto significa que os mecanismos de regulação destas políticas produzem resultados semelhantes sobre a desigualdade horizontal de gasto. Na verdade, ambas as políticas dispõem de mecanismos muito similares de regulação, que vinculam as receitas dos governos ao gasto nestas políticas, e condicionam transferências à oferta de serviços.

O mesmo não pode ser dito em relação às despesas não reguladas (habitação e urbanismo, e transporte), que já apresentavam patamares mais elevados de desigualdade no início da série. O Coeficiente de Gini na função "habitação e urbanismo" já era alto $(0,474)$ e se mantém bastante estável ao longo da série. Em 2006, o Coeficiente de Gini desta função era de 0,432 . No transporte público, a desigualdade horizontal de gasto também é crescente, com o aumento do Coeficiente de Gini em mais de 15\%, passando de 0,572, em 1996, para 0,663, em 2006.

Em suma, há um claro padrão de desigualdade de gasto entre as políticas implementadas pelos municípios brasileiros. Nas áreas de saúde e educação - políticas reguladas -, a desigualdade de gasto é bem mais reduzida, ao passo que as políticas não reguladas apresentam grande disparidade nos valores de gasto per capita.

Que mecanismos explicam este resultado? Observe-se que os Coeficientes de Gini das políticas reguladas têm valores muito próximos ao das receitas municipais. A desigualdade de gasto nas políticas reguladas, portanto, é resultado da combinação entre o resultado redistributivo da regulação federal sobre as receitas e das regras de regulação de suas despesas, que vinculam receitas a destinos de gasto. O índice é próximo porque a desigualdade de gasto também é afetada pelas transferências condicionadas universais, que obedecem a critérios alocativos distintos. Portanto, a ausência da regulação federal implicaria maior desigualdade de gasto entre as jurisdições.

Este resultado não é aleatório, ou sequer expressão de um comportamento caótico. Em vez disto, este é explicado pelo mecanismo de regulação empregada pela União para "amarrar" os governos locais nestas políticas; consiste em vincular as receitas municipais a estas funções de gasto, supervisionando-as por intermédio dos Tribunais de Contas. Reduzidos patamares de desigualdade estão associados à regulação 
federal, que vincula as receitas municipais, cuja desigualdade, por sua vez, é reduzida pelas transferências federais e pelas transferências condicionadas universais. Em outras palavras, a combinação de regulação das receitas municipais com regulação das despesas municipais tem como efeito mais uniformidade de gasto nas políticas reguladas. Em termos teóricos, redução das desigualdades territoriais supõe que a União opere simultaneamente funções regulatórias e redistributivas.

Por outro lado, os dados apresentados acima indicam que, a despeito deste efeito de convergência produzido pela regulação federal, há variações nas prioridades municipais de gasto, mesmo para as políticas reguladas. Isto significa que a autonomia dos governos locais para tomar decisões sobre suas próprias políticas opera no sentido da variação nos patamares de gasto. Em termos teóricos, a possibilidade de discordância, derivada da autonomia política dos governos locais, opera no sentido da desigualdade territorial.

A combinação destes dois fatores - isto é, centralização da autoridade combinada com possibilidade de discordância - implica que a regulação federal opera no sentido de produzir resultados centrípetos, ao passo que a autonomia dos governos locais opera no sentido de produzir desigualdade. Tal como na conhecida analogia da "queda do tijolo e a passagem do transeunte", é o efeito de combinação que melhor explica o efeito das relações central-local no federalismo brasileiro. Portanto, uma adequada interpretação do efeito da "natureza particular do federalismo brasileiro" supõe levar as duas dimensões em consideração. Na presença dos dois fatores (isto é, nas políticas reguladas), a desigualdade territorial está constrangida no interior de intervalos. $\mathrm{Na}$ ausência desta regulação, as chances de que uma política venha a ter prioridade são menores, bem como a desigualdade de gasto é maior.

\section{CONCLUSÕES}

As evidências apresentadas neste artigo não confirmam a proposição de que o federalismo brasileiro possa ser adequadamente descrito como autárquico e desprovido de coordenação. Caso nossas instituições federativas produzissem, de fato, um mundo tieboutiano, em que cada jurisdição tem uma estratégia dominante de competição com as demais, derivada de sua plena autonomia tributária e sobre políticas públicas, o resultado esperado seria uma "corrida para baixo" no gasto 
social. Cada jurisdição procuraria se livrar dos pobres, para investir em infraestrutura e atrair contribuintes ricos e firmas.

Diferente disto, os resultados expostos indicam prioridade no gasto em saúde e em educação, que beneficiam predominantemente os mais pobres, bem como grande desigualdade na prioridade às políticas de infraestrutura urbana. O mecanismo explicativo deste comportamento padrão é o papel de regulamentação e de supervisão desempenhado pela União.

Na mesma direção, em um federalismo dominantemente competitivo, alta desigualdade de receita entre as jurisdições seria o resultado mais provável. Este resultado não é encontrado no caso brasileiro, devido ao papel da União na redução das desigualdades de receita entre as jurisdições.

Estas evidências revelam que há um trade-off entre a redução das desigualdades territoriais e a plena autonomia dos governos locais. O papel redistributivo do governo federal parece ser uma condição para reduzir desigualdades interjurisdicionais de receita e, por consequência, a desigualdade de acesso dos cidadãos a serviços públicos no interior de um Estado-nação. Na ausência das transferências, a capacidade dos municípios brasileiros para prover serviços públicos seria altamente desigual.

Além disto, a regulação federal parece ser uma condição para "amarrar" subunidades independentes em torno de um dado objetivo nacional. O padrão de gasto dos governos locais - isto é, alta prioridade e baixa desigualdade nas políticas reguladas acompanhado de baixa prioridade e elevada desigualdade nas políticas não reguladas - demonstra claramente o impacto da regulação federal sobre as decisões dos governos locais.

Contudo, este não é necessariamente um jogo de soma zero, pois cada nível de governo desempenha distintos papéis. Enquanto a União compromete os governos locais com certas políticas, por meio de suas funções regulatórias - evitando assim uma corrida para baixo no gasto em saúde e educação -, os governos locais detêm autoridade sobre a execução das políticas. Além disto, sua autonomia política lhes permite a possibilidade da discordância. Como resultado, mesmo na presença da regulação federal, ainda há espaço para decisões por parte dos 
governos locais, derivadas quer de sua autonomia política quer de sua autoridade sobre a execução de políticas.

Assim, em vez de um jogo de soma zero, a combinação de regulação federal com a possibilidade de discordância por parte das unidades constituintes implica uma limitação ao pleno exercício da discordância. Isto é, a extensão da discordância tende a ser constrangida pela regulação federal, ao passo que a possibilidade de discordância explica as diferenças entre as jurisdições. A regulação federal opera no sentido da uniformidade, ao passo que a autonomia local opera no sentido da variação. Nestas condições, isto é, na presença simultânea de regulação federal e autonomia local, a desigualdade entre jurisdições tende a ser delimitada, tende a variar no interior de certos intervalos. Na presença das duas condições, a desigualdade territorial tende a ser limitada.

O impacto da regulação federal é uma das razões pelas quais não há relação entre o gasto dos governos subnacionais e a filiação partidária de seus respectivos governantes no Brasil ${ }^{17}$. Menos do que expressão da fragilidade programática dos partidos brasileiros, este resultado é expressão do fato de que a decisão sobre patamares de gasto é largamente afetada por fatores exógenos ao município. Independentemente de suas preferências ideológicas, e, mesmo, das preferências ideológicas do eleitorado local, prefeitos estão constrangidos a empregar suas receitas de acordo com normas previstas pela legislação federal. Dado que os orçamentos são fixos, os efeitos desta regulação afetam não apenas os patamares de gasto nas políticas reguladas, mas também os recursos disponíveis para as políticas não reguladas.

Na verdade, a ausência de relação entre patamares de gasto e preferências partidárias locais, é o resultado esperado da regulação federal. Se coalizões políticas favoráveis ao gasto em saúde e em educação (que beneficiam os mais pobres) fossem dominantes em todas as jurisdições brasileiras, não haveria razão para que a legislação federal obrigasse os prefeitos municipais a alocarem suas receitas nestas políticas. É justamente a crença de que este gasto não tenderia a ter prioridade que está na origem deste tipo de legislação. Portanto, a regulação federal visa a proteger determinadas políticas, a despeito da inferioridade numérica de eleitores ou da fragilidade política de constituencies locais cujas preferências priorizem o gasto nestas políticas. 
Dadas estas evidências, interpretar as transferências federais como meramente pork barrel tende a subestimar suas natureza, origens e resultados. A parte mais expressiva das transferências federais no Brasil tem sua origem no objetivo de reduzir desigualdades territoriais de capacidade de gasto. Estas foram (historicamente) um elemento central do processo de construção do Estado brasileiro, similarmente a outras federações, em que a ideia de uma comunidade nacional única prevaleceu sobre as demandas por autonomia regional. Já a Constituição de 1946 adotou as transferências intergovernamentais paralelamente a regras constitucionais que vincularam as receitas dos governos subnacionais a prioridades políticas nacionais. Longe de permitir a livre alocação local de receitas arrecadadas em outras jurisdições, a lógica subjacente a este arranjo teve o objetivo oposto, qual seja, limitar a margem de manobra dos governos locais para gastar seus próprios recursos de acordo com suas próprias prioridades. No arranjo atual, as transferências constitucionais, adotadas em 1988, foram combinadas à limitação da autoridade dos governos locais, a partir de meados dos anos 1990, de modo a garantir que as receitas locais sejam efetivamente destinadas a realizar objetivos políticos estabelecidos pelas arenas decisórias federais. Portanto, as políticas reguladas têm natureza distinta do pork barrel, pois visam a reduzir a plena autonomia alocativa dos governantes subnacionais, pois estão assentadas sobre a crença de que os governantes locais provavelmente não destinarão suas receitas a programas sociais caso tenham autonomia decisória para alocar livremente suas receitas.

A percepção de pertencimento a uma comunidade nacional única combinada à desconfiança deste compromisso por parte das elites locais fornece justificação normativa para a autoridade da União para regular as políticas executadas pelos governos subnacionais.

(Recebido para publicação em abril de 2010)

(Versão definitiva em setembro de 2010) 


\section{NOTAS}

1. Sobre este problema na República Velha, ver Hochmann (2006). Sobre a constituinte de 1946, ver Souza (1976). Sobre o período democrático 46-64, ver Santos (1987). Sobre a constituinte de 1987-88, ver Souza (1997). Sobre o regime democrático atual, ver Abrucio (1998) e Stepan (1999).

2. A importância desta relação foi assumida implicitamente por estudos econométricos que medem o impacto das transferências sobre as decisões de gasto dos governos municipais (Sakurai, 2009) e sobre as eleições locais (Ferreira e Bugarin, 2006). Este artigo, contudo, adota uma perspectiva mais abrangente. Assume que não são apenas as políticas distributivas do governo central que afetam as decisões dos governos locais. Diferentemente, este estudo examina o impacto da regulação federal sobre estas decisões; esta é definida como o conjunto da legislação federal sobre as políticas das unidades constituintes, a autoridade para supervisionar suas políticas, bem como a função de redistribuição de receitas entre jurisdições.

3. Embora este trabalho tome como objeto empírico os municípios, suponho que resultados semelhantes seriam encontrados caso estratégia analítica semelhante fosse adotada para analisar as decisões dos governos estaduais.

4. Em estudo sobre o processo de formação do Estado nacional na Itália e na Alemanha, Daniel Zibblat (2006) demonstra que diferentes trajetórias de construção do Estado nacional podem ser explicadas pelas percepções das elites centrais sobre a capacidade dos governos regionais para desempenhar funções governativas. Na origem, Bismarck e Cavour teriam preferências semelhantes com relação à adoção da fórmula federativa. Entretanto, o primeiro unificou regiões com fortes capacidades governativas, ao passo que, na Itália, a fragilidade administrativa das províncias sulistas teriam inviabilizado a adoção da fórmula federativa.

5. O conceito de desmercadorização refere-se à capacidade de as políticas sociais garantirem aos cidadãos (ou famílias) um padrão aceitável de vida, independentemente de sua inserção como mercadoria no mercado de trabalho (Esping-Andersen, 1990).

6. Para a discussão deste problema, ver: Afonso e Araújo (2006), Pinto (2007); Prado (2001); Rezende (2006).

7. Para uma explicação da lógica associada a cada um destas formas de transferência, ver Prado (2006: capítulo 1).

8. A Norma Operacional Básica (NOB) 1996/1998 - assim como as demais NOBs - condiciona transferências federais à adesão às normas do Ministério da Saúde. Adicionalmente, a NOB 96(98) reduziu a incerteza quanto ao fluxo das transferências, tornando crível que estas seriam efetivamente realizadas.

9. Esta breve descrição refere-se ao Fundo de Manutenção e Desenvolvimento da Educação Básica e de Valorização dos Profissionais da Educação (Fundeb), aprovado em 2006. Este substituiu o Fundo de Manutenção e Desenvolvimento do Ensino Fundamental e Valorização do Magistério (Fundef). Ambos derivaram de emendas constitucionais que condicionam a distribuição de recursos proporcionalmente à oferta de ensino por cada esfera de governo, no interior de cada estado. Para uma análise detalhada, ver Vazquez (2003) e Gomes (2008).

10. A série histórica permite evitar o viés analítico associado ao exame de pontos discretos no tempo. 
11. A Constituição Federal de 1988 determinou que os governos subnacionais devem destinar, no mínimo, 25\% de suas receitas de impostos e transferências para o ensino. Este mecanismo de regulação das finanças subnacionais não foi uma inovação da CF 88. A vinculação de receitas para a educação foi retomada (pois esta já constava da CF 46) pela Emenda Calmon, em 1983.

12. A Emenda Constitucional no 29/2000 definiu um patamar mínimo inicial, para 2000, de $7 \%$ das receitas municipais e estaduais a serem aplicadas em saúde, e um acréscimo de $5 \%$ sobre o montante empenhado pelo Ministério da Saúde em 1999. Nos anos seguintes, até 2004, os percentuais previstos para estados e municípios deveriam elevar-se até atingir 12\% das receitas estaduais e 15\% das receitas municipais, enquanto a participação da União seria corrigida pela variação nominal do Produto Interno Bruto (PIB).

13. Mais uma vez, adotar uma série histórica como unidade de observação permite evitar o viés analítico associado ao exame de pontos discretos no tempo. Além disto, começar a série histórica em 2002 permite desagregar as subfunções de interesse, o que não é possíve1 para o período anterior a 2001, com base nos dados disponibilizados pela Secretaria do Tesouro Nacional.

14. Os números dispostos no Gráfico referem-se ao código do município na classificação do Instituto Brasileiro de Geografia e Estatística (IBGE).

15. Iniciar a análise pelo ano de 1996 tem o propósito metodológico de permitir examinar o impacto da introdução da NOB 96/98 e do FUNDEF, em 1998, bem como da Emenda Constitucional 29/2000.

16. Até 2001, os dados contábeis dos municípios, disponibilizada pela Secretaria do Tesouro Nacional, agrega os gastos por função. A desagregação por subfunções ocorre apenas a partir de 2002. Para controlar a trajetória do gasto por um ponto no tempo anterior a 1998, a análise é realizada pela classificação funcional programática vigente até 2001. A análise por função afeta apenas marginalmente as inferências, porque os gastos municipais em cultura e saneamento são largamente inferiores ao gasto em educação e saúde.

17. Para uma análise deste problema para os estados brasileiros, ver Sátyro (2008). 


\section{REFERÊNCIAS BIBLIOGRÁFICAS}

ABRUCIO, Fernando. (1998), Os Barões da Federação. São Paulo, Hucitec/Edusp. e SOARES, Márcia M. (2001), Redes Federativas no Brasil: Cooperação Intermunicipal no Grande ABC. São Paulo, CEDEC/Fundação Konrad Adenauer Stiftung.

AFONSO, José Roberto Rodrigues e ARAÚJO, Erika Amorim. (2006), “Local Government Organization and Finance: Brazil", in A. Shah (ed.), Local Governance in Developing Countries. Washington, The World Bank, pp. 1-38.

ALMEIDA, Maria Hermínia Tavares de. (2005), “Recentralizando a Federação?”. Revista de Sociologia e Política, no 24, pp. 29-40.

ALMOND, Gabriel A. e POWELL JR., G. Bingham. (1978), Comparative Politics: Systems, Process, and Policy. (2 ed.). Boston, Little, Brown and Company.

ARRETCHE, Marta. (2000), Estado Federativo e Politicas Sociais: Determinantes da Descentralização. Rio de Janeiro, Revan.

. (2005), “Quem Taxa e Quem Gasta: A Barganha Federativa na Federação Brasileira". Revista de Sociologia e Política, no 24, pp. 69-86.

. (2007). "The Veto Power of Territorial Governments in Brazil: Political Institutions and Representatives Voting Behaviour". Brazilian Political Science Review, no 2, pp. $40-73$.

. (2009). “Continuidades e Descontinuidades da Federação Brasileira: De Como 1988 Facilitou 1995". DADOS, vol. 52, № 2, pp. 377-423.

BANTING, Keith. (2006). “Social Citizenship and Federalism: Is a Federal State a Contradiction in Terms?", in S. Greer (ed.), Territory, Democracy, and Justice. Regionalism and Federalism in Western Democracies. London, Pallgrave Macmillan, pp. 44-66.

e CORBETT, Stan. (2002), “Health Policy and Federalism: An Introduction”, in K. Banting e S. Corbett (eds.), Health Policy and Federalism: A Comparative Perspective on Multi-level Governance. Kingston, CA, Queen's University, Institute of Intergovernmental Relations, pp. 1-38.

BIDERMAN, Ciro. (2005), "Políticas Públicas Locais no Brasil”, in P. Arvate e C. Biderman (orgs.), Economia do Setor Público no Brasil. Rio de Janeiro, Elsevier, vol. 1, pp. 462-492.

BUCHANAN, James M. (1995), “Federalism as an Ideal Political Order and an Objective for Constitutional Reform". Publius: The Journal of Federalism, vol. 25, no2, pp. 19-27.

CARVALHO, José Murilo de. (2001), Cidadania no Brasil. São Paulo, Civilização Brasileira.

DRAIBE, Sônia. (1985), Rumos e Metamorfoses.São Paulo, Paz e Terra.

(1989), “As Políticas Sociais do Regime Militar Brasileiro: 1964-84”, in G. D. Soares e M. C. D’Araújo (orgs.), 21 Anos de Regime Militar: Balanços e Perspectivas. Rio de Janeiro, FGV Editora, pp. 271-309.

ESPING-ANDERSEN, Gösta. (1990), The Three Worlds of the Welfare Capitalism. Princeton, Princeton University Press. 
FERREIRA, Ivan F. S. e BUGARIN, Mauricio S. (2006), “Transferências Voluntárias e Ciclo Político-Orçamentário no Federalismo Fiscal Brasileiro". IBMEC Working Paper, no 16.

GOMES, Sandra Cristina. (2008), Fatores Explicativos das Diferentes Estratégias de Municipalização do Ensino Fundamental nos Governos Subnacionais no Brasil. Tese de Doutorado em Ciência Política, FFLCH/USP, São Paulo.

HOCHMAN, Gilberto. (2006). A Era do Saneamento. As Bases da Política de Saúde Pública no Brasil. São Paulo, Hucitec.

LAMOUNIER, Bolivar. (1992), “Estrutura Institucional e Governabilidade na Década de 1990", in J. P. dos Reis Velloso (org.), O Brasil e as Reformas Políticas. Rio de Janeiro, José Olympio, pp. 102-38.

LEAL, Victor Nunes. (1949), Coronelismo, Enxada e Voto. São Paulo, Editora Alfa-Ômega Ltda.

LIJPHART, Arend. (1984), Democracies. Patterns of Majoritarian and Consensus Government in Twenty-One Countries. New Haven, Yale University Press.

MANOW, Philip. (2005), "Germany: Co-Operative Federalism and the Overgrazing of the Fiscal Commons", in H. Obinger, S. Leibfried e F. G. Castles (eds.), Federalism and the Welfare State. New World and European Experiences. Cambridge, Cambridge University Press, pp. 222-62.

MARSHALL, Thomas H. (1967), "Cidadania e Classe Social”, in Cidadania, Classe Social e Status. Rio de Janeiro, Zahar.

MOTA, Carlos Guilherme (org.). (1982), Brasil em Perspectiva. São Paulo, Difel, vol. 1.

NUNES, Edson. (1997), A Gramática Política no Brasil: Clientelismo e Insulamento Burocrático. Rio de Janeiro, Zahar Editores.

OBINGER, Herbert. (2005). "Austria: Strong Parties in a Weak Federal Polity", in H. Obinger, S. Leibfried, e F. G. Castles (eds.), Federalism and the Welfare State. New World and European Experiences. Cambridge, Cambridge University Press, pp. 181-262.

OBINGER, Herbert, LEIBFRIED, Stephan e CASTLES, Francis G. (eds.). (2005), Federalism and the Welfare State. New World and European Experiences. Cambridge, Cambridge University Press.

OLIVEIRA, Maria Lúcia de. (1977), "A Tendência à Centralização e o Fenômeno do Autoritarismo no Brasil". DADOS, no 15, pp. 83-99.

PEREIRA, Carlos e MUELLER, Bernardo. (2002), “Comportamento Estratégico em Presidencialismo de Coalizão: As Relações entre Executivo e Legislativo na Elaboração do Orçamento Brasileiro". DADOS, vol. 45, no 2, pp. 265-301.

PETERSON, Paul E. (1995). The Price of Federalism. Washington, The Brookings Institution.

PIERSON, Paul. (1995), "Fragmented Welfare States: Federal Institutions and the Development of Social Policies". Governance: An International Journal of Policy and Administration, vol. 8, no 4, pp. 449-478. 


\section{Marta Arretche}

PINTO, Sol Garson. (2007), Regiões Metropolitanas. Obstáculos Institucionais à Cooperação em Políticas Urbanas. Tese de Doutorado em Planejamento Urbano e Regional, IPPUR/UFRJ, Rio de Janeiro.

PRADO, Sérgio. (2001), Transferências Fiscais e Financiamento Municipal no Brasil. Relatório de Pesquisa, Projeto Descentralização Fiscal e Cooperação Financeira Intergovernamental. EBAP/Fundação Konrad Adenauer.

. (2006), Equalização e Federalismo Fiscal: Uma Análise Comparada. Rio de Janeiro, Konrad-Adenauer-Stiftung.

RAZIN, Eran. (2007), “Introduction: Deconcentration of Economic Activities Within Metropolitan Regions: A Qualitative Framework for Cross-national Comparison”, in E. Razin et alii (eds.), Employment Deconcentration in European Metropolitan Areas. Toronto, Springer, pp. 1-28.

REZENDE, Fernando. (2006), “Os Desafios do Federalismo Fiscal”, in F. Rezende (ed.), Desafios do Federalismo Fiscal. Rio de Janeiro, FGV Editora, pp. 11-23.

RIBEIRO, Leandro Molhano. (2005), Partidos e Políticas Sociais nos Municípios Brasileiros. Tese de Doutorado em Ciência Política, IUPERJ/UCAM, Rio de Janeiro.

SAKURAI, Sérgio Naruhiko. (2009), “Ciclos Políticos nas Funções Orçamentárias dos Municípios Brasileiros: Uma Análise para o Período 1990-2005, via Dados em Painel". Estudos Econômicos, vol. 39, pp. 39-58.

SANTOS, Wanderley G. dos. (1979), Cidadania e Justiça. Rio de Janeiro, Ed. Campus.

. (1987), Crise e Castigo. Partidos e Generais na Política Brasileira. Rio de Janeiro, Editora Vértice/IUPERJ.

SÁTYRO, Natália Guimarães Duarte. (2008), Política e Instituições e a Dinâmica das Políticas Sociais nos Estados Brasileiros: Uma Análise após a Redemocratização. Tese de Doutorado em Ciência Política, IUPERJ/UCAM, Rio de Janeiro.

SELLERS, Jefferey M. e LIDSTRÖM, Anders. (2007), “Decentralization, Local Government, and the Welfare State". Governance, vol. 20, no 4, pp. 609-632.

SIKKINK, Kathryn. (1993), Ideas and Institutions: Developmentalism in Brazil and Argentina. Ithaca, Cornell University Press.

SCHWARTZMAN, Simon. (1982), Bases do Autoritarismo Brasileiro. Brasília, UnB Editora.

SHAH, Anwar (ed.). (2006), Local Governance in Developing Countries. Washington, The World Bank.

SOUZA, Celina. (1997), Constitutional Engineering in Brazil: The Politics of Federalism and Decentralization. Houndmills/London/New York, Macmillan/St. Martin's Press.

SOUZA, Maria do Carmo Campello de. (1976), Estado e Partidos Políticos no Brasil (1930-1964). São Paulo, Alfa-Ômega.

STEPAN, Alfred. (1999), “Para uma Nova Análise Comparativa do Federalismo e da Democracia: Federações que Restringem ou Ampliam o Poder da Demos". DADOS, vol. 42, no 2, pp. 197-251.

TIEBOUT, Charles. (1956), "A Pure Theory of Local Expenditures". The Journal of Political Economy, vol. 64, no 5, pp. 416-424. 
VAZQUEZ, Daniel Arias. (2003), Educação, Descentralização e Desequilíbrios Regionais: Os Impactos do FUNDEF. Dissertação de Mestrado em Economia, Instituto de Economia da Unicamp, Campinas, SP.

WEINGAST, Barry. (1995), “The Economic Role of Political Institutions: Market-Preserving Federalism and Economic Development". The Journal of Law, Economics, E Organization, vol. 11, no 1, pp. 1-31.

WILDAVSKY, Aaron. (1984), “Federalism Means Inequality: Geometry, Political Sociology, and Political Culture", in R. T. Golembiewski e A. Wildavsky (eds.), The Costs of Federalism. New Brunswick/London, Transaction Books, pp. 55-69.

ZIBLATT, Daniel. (2006), Structuring the State: The Formation of Italy and Germany and the Puzzle of Federalism. Princeton, Princeton University Press. 


\section{ABSTRACT \\ Federalism and Territorial Equality: A Contradiction in Terms?}

The study explores the relationship between federalism and territorial inequality, taking Brazil as the object of analysis. The conclusion is that there is a trade-off between territorial inequality reduction and the full autonomy of local governments. The central government's redistributive role seems to be a condition for reducing revenue inequality between jurisdictions, and so reducing inequality in citizens' access to public services requires the central government to perform redistributive and regulatory role. On the other hand, local autonomy pushes toward inequality. Hence, federal regulation and local autonomy are combined in a given polity, the result tends to be bound inequality.

Key words: federative state; municipalities; public policies; territorial inequality

\section{RÉSUMÉ}

Fédéralisme et Égalité Territoriale: Une Contradiction entre les Termes?

Dans ce travail, on examine les relations entre fédéralisme et inégalité territoriale, le Brésil étant l'objet d'étude. On conclut qu'il y a un compromis entre la réduction des inégalités territoriales et la pleine autonomie des autorités locales. Le rôle redistributif du gouvernement central semble une condition pour réduire des inégalités interjuridictionnelles du revenu et, par conséquent, l'inégalité d'accès des citoyens aux services publics dans le cadre d'un état nation. En outre, le produit de l'autonomie local is inégalité. Donc, quand on trouve régulation fédérale et autonomie locale, le resultat le plus probable est que l'inégalité soit controlé au-dedans de certains intervalles.

Mots-clé: État fédératif; municipalités; politique publique; inégalité territoriale 